\title{
The Reason-Giving Force of Requests
}

\author{
Peter Schaber ${ }^{1}$ (D)
}

Accepted: 16 March 2021/ Published online: 24 March 2021

(C) The Author(s) 2021

\begin{abstract}
How do we change the normative landscape by making requests? It will be argued that by making requests we create reasons for action if and only if certain conditions are met. We are able to create reasons if and only if doing so is valuable for the requester, and if they respect the requestee. Respectful requests have a normative force - it will be argued because it is of instrumental value to us that we all have the normative power of creating reasons by making requests. The normative power has the potential for creating and shaping valuable interactions and relationships for the requester and the requestee. This potential could not be realized if we did not have the normative power of making requests. It will also be shown why this account of the normative force of requests should be preferred to the two alternative accounts of the reason-giving force of requests that have been put forward by James H.P. Lewis and David Enoch.
\end{abstract}

Keywords Requests $\cdot$ Creating reasons $\cdot$ Triggering reasons $\cdot$ Non-obligatory reasons $\cdot$ Obligatory reasons

\section{Introduction}

We are able to change the rights and obligations we have towards each other by means of certain actions. We can do this by promising, by consenting, by giving orders, or by making demands. By promising you put yourself under a duty. By giving orders you put - given that you have the required authority - another person under a duty. By consenting you release the other person from a duty. We also seem to change the reasons for action other people have by making requests. Consider the following example: John and Jill are colleagues at the same department working on similar issues. John asks Jill to read a draft of a paper he is working on. It seems that this gives Jill a reason to read John's draft, a reason Jill did not have before. It seems that the reason is brought about by John's request, by his asking Jill to read his draft. Moreover, the reason brought about by the request is brought about in a special way, which

Peter Schaber

schaber@philos.uzh.ch

1 University of Zurich, Zollikerstr. 117, 8008 Zurich, Switzerland 
Enoch calls reason-giving in a "robust sense" (Enoch 2011: 1). Enoch thinks that this form of reason-giving has to be distinguished from a non-robust form of reason-giving. Consider an example Enoch presents in his paper "Giving Practical Reasons" (Enoch 2011: 4): A grocer demands a higher price for his milk. The price change changes the weight of the reasons one has to buy milk from this shop. The request case seems to be different: John creates a reason for Jill by making a request. It seems that the act of request creates a reason for Jill to do as requested. Hiking up the price creates a reason. The reason it creates is ultimately grounded in a further fact, a fact about the customer's well-being. The reason the request creates is ultimately grounded in the request, not in a further fact. It is John's asking Jill to read his draft that provides her with a reason to do so.

But is this really the normative work done by requests? This question can only be answered if we know what the normative mechanism is that is triggered by making requests. This paper makes a suggestion as to what this normative mechanism is and why the account that will be developed should be preferred to the two accounts of the normative force of requests that have been put forward by James H.P. Lewis and David Enoch. ${ }^{1}$

The paper has six parts. In Section 2 I will address the question of what it means to make a request. I will then present in Section 3 my account of the normative force of requests. The normative force of requests is not simply based on the value the power has for the requester. Others' having the power of creating reasons by making request is valuable for the requestee as well. It is valuable for us that others have the normative power to create reasons by making requests that are respectful. That they have this normative power is valuable because it opens up a potential for valuable interactions and relationships. It is not the case that each request is valuable for the requestees. Rather, the requesters' power is valuable for the requestees because it has the potential for creating valuable forms of interaction with others, to which we would have no access if we did not have the normative power of creating reasons by making requests. In Section 4 I will deal with the question of whether requests create only nonobligatory reasons for action. I will then address the issue of whether the proposal can and should account for the discretionary quality of requests. In Section 5 I will critically examine and reject the account of the reason-giving force of requests developed by James Lewis according to which requests create reasons for action if the requestee (the request-receiver) has discretionary value-attitudes towards the requester (the person who is asking the other person). In Section 6 I will discuss Enoch's account according to which requests trigger conditional reasons and argue that the view of the normative force of requests he provides us with needs to be complemented by an account of the normativity of the background conditions. Section 7 concludes.

\section{Making Requests}

Let me first clarify what I take requests to be: Requests are acts of second-personal address. A person makes a request by performing a communicative act. The communicative act expresses a desire of the requester that the requestee does or omits something. If John asks Jill to read his

\footnotetext{
${ }^{1}$ Other authors such as Raz (1975: 82), Owens (2012: 85), and Lance and Kukla (2013) talk about requests creating reasons for action without actually addressing the question of how these reasons are brought about by requests. Gläser, on the other hand, argues that requests do not create additional reasons, they rather put the requestees under an obligation see Gläser (2019: 42).
} 
draft he wants Jill to do so. But requesting is not just expressing a desire that another person does or omits something. John might want Jill to read his draft but he might not want to ask her to do so. John could say to her: "I want you to read my draft (your comments are always so helpful) but I am not going to ask you”. As Joseph Raz rightly puts it:

"It would be wrong to regard requests as mere communication of information that the speaker ... needs or wants something and that the speaker wants the addressee to help in getting it. Although every request at least implies such information, it is possible to communicate the information without requesting ... It is possible ... to tell a person that, while I would like him to do something for me, I am not asking and am not going to ask him to do it" (Raz 1986: 36).

John might not want to ask Jill for various reasons. He might not want to ask her because he might not want Jill to read the draft because he has asked her to do so. Or he might not want to ask her because he might feel that he is not in a position to ask her, just to mention two reasons for not asking someone to do or to omit something.

Asking another person to do $\mathrm{x}$ is more than informing her that you want her to do $\mathrm{x}$. If you ask another person to do $\mathrm{x}$ you want your will that she does $\mathrm{x}$ to be a reason for her to do $\mathrm{x}$. It is important to note that making a request is not simply informing another person that one has a desire that the other person does x. You want your will to be a reason for the addressee. "This account explains why one might request even when one knows that the other person knows of one's need and of one's desire for help" (Raz 1986: 37).

I agree with Raz and Lewis that by requesting something we want to make a normative difference. We want to create an additional reason for the addressee to do as requested. As Raz puts it:

"A person who makes a request intends his making the request to be a reason for the recipient to comply with it" ( $\operatorname{Raz} 1975: 83){ }^{2}$

Thus this is then what I take requests to be:

(R) A person who makes a request wants her communicated will that the addressee do or omit something to be a reason for the addressee.

The normative aim is made explicit by certain forms ways of addressing yourself to another person: John might ask Jill "Could you please read my draft?" or "I would be very happy if you could read my paper" or "Would you mind doing this for me?". These are ways of making the normative aim of the communicative act of making a request explicit.

The requestee can do as requested because she was asked to do so. She can also do as requested for other reasons (Jill might read John's draft because she interested in learning more about his theory). Thus, requests can be complied with for two different kinds of reasons: for request-dependent and for request-independent reasons:

(RDR) Request-dependent reasons are those reasons to do what has been requested that are created because one was asked to do so. ${ }^{3}$

\footnotetext{
${ }^{2}$ See also Raz (2009: 14). James Lewis has a similar view: "A request is an attempt by an addressor to create and communicate a non-obligatory reason for the addresse(s) to perform an action" (Lewis 2018: 2). Lewis thinks that the requester has the intention to create a non-obligatory reason for the requestee.

${ }^{3}$ This is what Lance and Kukla have in mind when they write: "The output of a successful request is that the target now has a specific sort of reason to do what was requested, but it is essential to the notion of a request that this reason is not an obligation. An imperative has failed in its pragmatic function if the target does not acknowledge that she has an obligation to act as ordered" (Lance and Kukla, 2013: 460).
} 
(RIR) Request-independent reasons are those reasons to do what has been requested that

exist independently of having been asked to do so.

We should note here that we can also ask someone for something without having a desire that the addressee will grant the request. John could ask Jill to read his draft simply out of politeness, that is, because John knows that Jill would be offended if he did not ask her. John might hope that his request will be turned down by Jill. The question is: Did John make a request? You do not make a request if you do not represent yourself as having a desire to create a reason and a desire that the other person acts on it. But you can represent yourself as having a desire to create a reason for the addressee without actually having it. Then you are making a request. John makes a request because he wants to be polite. If Jill learns that John does not want to create a reason for her, she will no longer take his request as a reason for her to read his draft.

\section{The Value of Creating Reasons by Making Requests}

What is the normative mechanism triggered by requests? Consider this case: A Japanese tourist, let us call him Yuma, got lost and needs to catch the train. He is asking John the way to the station. John never met Yuma before and tells him the way to the station. Asked by a friend why he did it he says "because he asked me to tell him the way to the station". John took Yuma's request as a reason for acting. Yuma asks John to tell him the way in order to give him a reason to do. That is, Yuma's request is meant to provide John with an additional reason to do as requested. So what happened here seems to be best described as an act of trying to give John a reason by asking him to do something, a reason John did not have before. Of course, John might have had request-independent reasons to tell Yuma the way to the station but he did not have a request-dependent reason to do so.

What is it that provides John with an additional reason to do as requested? To motivate my view, let me mention two suggestions that might be made here: a) One could say that Yuma's request informs John about a request-independent reason John has to tell Yuma the way to the station. Yuma has to catch the train. John has a reason to make this possible by telling him the way. One could alternatively say b) that Yuma's request informs John about Yuma's desire that John tells him the way to the station and that this desire provides John with a reason to do as requested.

Let us first have a closer look at a): On the first view Yuma's request informs John that there is a request-independent reason for John to do as requested. If this was the normative work done by asking others to do something the act of asking another person itself would have no normative force. Yuma's asking John would have a purely epistemic function of making John aware of the fact that there is a request-independent reason to tell him the way to the station. If one thinks that this is what requests do one has difficulties to account for the difference between informing someone about a desire that someone does something and asking someone to do something. On this view it would not make sense to say "I want you to do $\mathrm{x}$ but I am not going to ask you to do x". Thus the proposal faces a serious difficulty. However, the statement does make sense if one understands requests as attempts to make a normative difference by communicating that one wants to make a normative difference. Consider the Jill/John case: John aims at giving Jill a reason to read his draft by 
communicating that he wants his request to be a reason for her. Thus it makes sense to say "I want you to read my paper but I do not want to create a reason for you do so by making a request".

Let us have a look at b): On the second view the reason John has to tell Yuma the way to the station is provided by Yuma's desire that John tells him the way to the station. Thus, Yuma's request informs John about Yuma's desire that he does as requested. The second view faces the same difficulty as the first. Yuma's desire might provide John with a reason. ${ }^{4}$ But if the desire expressed by the request is the reason to do as requested the communicative act informs the requestee that the requester that there is a request-independent reason to do so. Asking John to do so would then do no normative work. It would only have an epistemic function. But if one holds this view one can again not account for the difference between informing about a desire and asking someone to do something.

Here is a more promising proposal: We create reasons by asking others to do or to omit something. Acts of request create reasons for action or omission for the addressees. This is what is going on when we make requests. Take our case again: Yuma wants his asking to be a reason for John to tell him the way to the station. It would be good for him if John did what Yuma wants him to do. And it would be thus good for him if he was able to provide John with a reason to do so. Thus, it is of value for him to be able to provide John with an additional reason. It is valuable for him because it makes it more likely that he gets what he has reason to want, namely to know the way to the station. It makes it more likely because we are able to respond to reasons. If we see that we have a reason to do $\mathrm{x}$ we might do $\mathrm{x}$ for this reason. The normative reason becomes a motivating reason, provided the agent is reason-responsive.

One might think that my ability to get another person to do $\mathrm{x}$ is valuable for me not my ability to create a normative reason for her to do so. It is true that my ability to get her to do $\mathrm{x}$ is valuable for me. Creating normative reasons is also valuable, not intrinsically but instrumentally valuable. It is valuable to create normative reasons because it makes it more likely to get others to do what you want them to do. Creating normative reasons is therefore not in itself valuable but because it contributes to something else that is valuable. There are other ways of getting people to do what you want them to do. I can demand that you do what I want you to do. I may manipulate you into doing as I please or force you by threating you to do as I want you to do. But to change the normative situation by demanding I need an authority I often do not have. And if I manipulate or force you into doing what I want you to do I wrong you, which I should not and generally do not want to. So it is especially valuable to be able to robustly give you a normative reason.

It is in general valuable for us if others do what we have reason to want them to do: providing us with helpful comments on our papers, informing us about directions, giving us good advice on future projects and many other things more. It is the value of being able to create reasons that makes it the case that making requests is the exercise of a normative ability. That one has this ability because it is valuable for the requester to create reasons for others is, however, only part of the story of the normative mechanism triggered by making requests. The following makes it clear that something has to be added.

It would be good for me to have the power to make others to owe me anything I want them to owe me. But I do not have this power. The fact that having the power would be good for me does not mean that I have this power. The normative force of requests is not simply based on the value the normative power of requests has for the requester. Others' having the power of

\footnotetext{
${ }^{4}$ I will stay neutral on the issue of whether desires provide other persons with reason to act.
} 
creating reasons by making requests is valuable for the requestee as well. Why is this the case? There are two things to be said here: a) The normative power others have can only be valuable if the requests respect the requestee. They respect their addressees if what they ask for does not disregard their rights and interests. The content of a request can be in many ways disrespecting the requestee, for instance, by asking for favors that are degrading for her. Think of asking someone to kneel before you in public. The content of a request can also be disrespectful by not taking the addressee's interests into account. Think of a request to read a 800 page manuscript over the week-end. The content of a request can also be disrespectful by being a request for immoral acts (“Could you please help me to steal his money?") aiming at wronging third parties. They only create reasons if they are respectful with respect to their form as well as their content. This sets limits on the creating reasons force of requests. This is a necessary condition for the power being valuable for the requestee.

b) Requests that are respectful have, however, a normative force because it is valuable for all of us that others have the normative power of creating reasons by making requests that are respectful. That they have the normative power of making requests is valuable for all of us because it opens up a potential for valuable interactions and relationships. ${ }^{5}$ Complying with certain requests might be beneficial for the requestees. John's request might be the start of a fruitful scientific co-operation between Jill and John. Or it might be part of an ongoing scientific cooperation keeping it alive, a cooperation Jill also benefits from. A request might be the start of friendship or again something that keeps the friendship going. We often have reasons to be happy about being asked.

However, not all requests are beneficial for the requestees. Complying with a particular request might be burdensome. This might make one wonder why all requests that are respectful create reasons. They do so not because they are valuable but rather because it is valuable that others have the normative power to create reasons by making requests. Even if it is burdensome to comply with a particular request the power others have is valuable because it has the potential for valuable future interactions and relationships. To read John's paper might not be beneficial for Jill but it allows her to ask John for favors in the future. Or it might be the start of a personal relationship. To tell Yuma the way to the station might not be valuable for John but the next time a tourist asks for directions might be the beginning of an interesting chat on the meaning of life. In sum, the normative power others have of creating reasons by making requests opens up the potential for creating valuable forms of interaction and relationships with them to which we would otherwise have no access.

It is valuable for requesters as well for the requestees that we all have the normative power to create reasons in respectful ways by making requests. One might think that further conditions have to be met and argue that requests create reasons only if the requester and the requestee have a personal relationship. ${ }^{6}$ Thus, if my partner asks me to do something I have a reason to do as requested. The same arguably applies to requests I am asked to comply with

\footnotetext{
${ }^{5}$ One might think that the inference from 1) "it would be valuable if people had normative power p to 2) "people have normative power p" is a non sequitur (see also Enoch 2009). Is the alleged inference a kind of wishful thinking? It is true that we don't have every ability it would be valuable to have (we are not able to fly like birds even though it would be valuable to be able to do so). Normative abilities, however, are neither physical nor cognitive abilities. We do not have them due to an evolutionary process. We need another kind of explanation for normative powers. The given value explanation is such an alternative explanation. It explains a practice we are all familiar with, the practice of taking requests as reason-providing. The explanation tries to make sense of this practice. I think that the value explanation developed in this paper is successful in doing so.

${ }^{6}$ I owe this point to Jay Wallace.
} 
by friends, family members and possibly colleagues. And because there Yuma and John do not have a personal relationship Yuma's request does - on this view - not create an additional reason for John to do as requested. He might have a request-independent but no requestdependent reason to do so. Yuma's request would just inform John that there is a requestindependent reason to tell Yuma the way to the station. Yuma's request had in this case only an epistemic function. On this view no normative work was done by Yuma's request, that is by his asking John to tell him the way to the station.

But why should Yuma not be able to create a reason for John by making a request, given that they have no personal relationship? Yuma wants his asking John to make a normative difference. And a plausible account can be given of when his attempt to make a normative difference is successful: It is successful because Yuma has - as everyone else - the normative power to create reasons by making requests which respect the requestee. It is not clear why the further condition of standing in a personal relation with Yuma has to be met to provide requests with a genuine reason-giving force.

Consider this example: Imagine that Yuma wants to know why the dials of church clocks are so large in this city. John by chance knows why and also that Yuma likes to know why this is the case. It would take some time to explain it to Yuma. Yuma asks John whether he could explain it to him. John has a reason to do so and it is not a reason he already had before he was asked to explain it to Yuma. Even if Yuma's desire provides John with a reason, Yuma wants to make a normative difference by making his request. By doing so he does not want to inform John that he has the desire that John tells him the way to the station. If Yuma asks John he does so because he wants to give John a reason to explain it to him, a reason he would otherwise not have. It makes sense to ask strangers, but it can only make sense if the reason-creating intention of making requests can be successful.

\section{Non-Obligatory Reasons?}

What kind of reasons do request provide us with? Are they providing us only - as Lewis thinks - with non-obligatory reasons or also with obligatory reasons? A reason is non-obligatory if it would not be blameworthy for one not to act on it, and obligatory if it would be blameworthy not to act on it. ${ }^{7}$ Do requests only create non-obligatory reasons? Consider this: Jill might have an obligatory reason to read the paper once John has requested her to do so, because John has read many of her papers. Thus there is an obligation of gratitude triggered by John's request. Jill has an obligation to read John's paper because of what he did for her in the past. What happens here is this: John's request creates a reason in a robust sense. It creates a requestdependent reason for Jill to read his paper. The reason created by his making the request is a non-obligatory reason. His request creates at the same time an obligatory reason by triggering a conditional obligation of gratitude. The request creates this obligatory reason in a non-robust sense. It would not create this reason if there was no conditional obligation in the background. It would merely create a request-dependent reason for Jill. Obligatory reasons are brought about by triggering a conditional obligations. Jill's obligatory reason is brought about by triggering the conditional obligation to 'read John's paper if he asks for it'.

Is the fact that requests can create obligatory reasons a problem for my proposal? I ask this question because - as I have already noted - Lewis thinks that a theory of requests should be

\footnotetext{
${ }^{7}$ I am using here the same conception of obligatoriness as Lewis does in his paper.
} 
able to account for the discretionary quality of requests. My account is able to do so. Requests have a discretionary quality by creating request-dependent reasons. But as the example above shows they can also create obligatory reasons. ${ }^{8}$ John might be well aware of the fact that his request will create an obligatory reason to do as requested by triggering the obligation of gratitude Jill has towards John. It seems we often make requests while knowing that they will create an obligation. But this is not a problem for my account. Requests create non-obligatory reasons in a robust sense. However, they can create obligatory reasons in a non-robust sense, by triggering conditional obligations. John's request provides Jill with an additional reason to satisfy her duty of gratitude.

The reasons requests create have always the same weight. It is true that some requests are more important than others. Take the case of my partner asking me to do the shopping again. Imagine that at the same time my neighbor asks me to do the same for him. Both requests are providing me with reasons to comply with them. It seems, however, that my partner's request is more important than the neighbor's request. However, I think that these requests provide me with the same reason. The normative difference that obtains between the two has to do with normative weight the request-independent reasons have that are in play in such situations. The fact that my partner wants me to do the shopping gives me a stronger reason than the fact that my neighbor wants me to the shopping for him. Her request is more important because - as I assume - her interests count for more for me than the interests of my neighbor. Their requests create both an additional reason for me to do the shopping. This is not where the normative difference comes from. The normative difference is due to the different weight the desires have that are expressed by the two requests. My partner's desire that I do the shopping counts for more than the desire my neighbor has that I do this for him. This is why her requests is more important for me than the request my neighbor made.

\section{Lewis' Account}

Let us compare this account of the normative force of requests with the two alternative accounts that have been put forward by Lewis and Enoch. Let me start with Lewis' account (Lewis 2018). On Lewis' view the requestee has a reason to do as requested if two conditions are met: if a) the requestee was requested to do or omit something and b) the requestee "places sufficient discretionary value" (Lewis 2018: 12) in the person who asked her to do (or omit) something. The discretionary value is understood as a value the requestee is not obliged to place in the requester: "these are attitudes that one is not obliged to hold" (Lewis 2018: 12). And if the requester does not put value in the requester she does not have a reason to do as requested. The request creates a reason by way of the requestee placing value in the requester.

On this view Yuma's request provides John with a reason if and only if John places sufficient discretionary value in Yuma.

Lewis thinks that this proposal can account for the discretionary quality of requests. It is up to the requestee to decide whether she complies with the request. This is how requests differ from commands. Commands are attempts to put others under a duty, requests attempts to provide others with a reason. Lewis thinks that his account of the reason giving force of request can explain why this is the case (Lewis 2018: 14): Requests have a discretionary quality because they are based on valuing-attitudes towards the requester the requestee is not

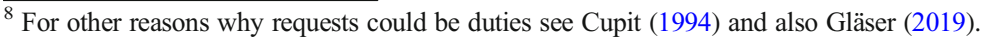


obliged to have. " $(\mathrm{O})$ ne intends for the other to treat this request as a reason, but not for them to treat it as itself conclusively instructing them. We ask them to $\Phi$, and thereby acknowledging that whilst our wishes are clear, the matter of whether to $\Phi$ or not is up to them" (Lewis 2018: 11). The request gives the requestee a reason if the requestee has certain valuing-attitudes towards the requester. It is up to the requestee to acquire these attitudes.

On this account it is not up to the requester to create a reason for the requestee. Lewis argues that when we make request we sometimes "implicitly appeal to the addresses to value us" (Lewis 2018: 13), appeals that might sometimes be successful. Yuma might indicate that he is desperate and hope that this prompts John to feel pity for him. If he is successful John has a reason, if this is not the case John has no reason to do as requested.

The reason giving force of requests is on this account not limited to requests of people the addressees already know. Lewis cites the case of two strangers, Carrie and Anita. Carrie is looking for a place to hide, knocks on Anita's door asking her whether she can come in without explaining why (Lewis 2018: 13). Carrie appeals to Anita "to take up some valuingattitude" (Lewis 2018: 13) and might well be successful in doing so. The value attitude might be "admiration, affection, pity, some kind of endearment" (Lewis 2018: 13). If Anita takes up one of these attitudes, Carrie's request is a reason for Anita to let her in. ${ }^{9}$

Lewis thinks that it is a "central merit of the account that I am proposing is its capacity to explain the sense in which the reasons presented in requests are discretionary" (Lewis 2018: 14). He understands discretionary reasons as non-obligatory reasons. Requests provide addressees with non-obligatory reason because they are based on value-attitudes of the requesters they are not obliged to have.

Is the fact that Lewis' proposal is able to account for the discretionary quality of request a reason to accept it? It has to be noted that my proposal can account for the fact that requests create non-obligatory reasons. The request-dependent reasons are non-obligatory reasons. On my view requests create reasons whereas on Lewis' view they only create reasons if the requestee places value in the requester. But I do not think this is a problem for my account because it is not clear whether such a further condition has to be satisfied to provide request with a normative force. An account of requests has to account for the fact that the requestdependent reasons are non-obligatory. And this is what my proposal does.

Moreover, it is not clear whether Lewis' account is really able to account for the discretionary quality of requests. On his view Anita has only a reason to let Carrie in if Anita feels, for instance, pity for Carrie. This would be a case of having a certain value-attitude towards Carrie. Anita places discretionary value in Carrie by feeling pity for her. Her valuing provides her with a non-obligatory reason to let Carrie in. ${ }^{10}$

The proposal is based on the view that "valuing $\mathrm{X}$ is having a favorable attitude towards $\mathrm{X}$ such that X can be the source of reasons for action" (Lewis 2018: 6). The proposal would face difficulties if an alternative view according to which valuing-attitudes would only provide us with reasons if they were appropriate. It might not be appropriate for Anita to feel pity for Carrie. The value she places in Carrie would then not be the value she should place in her. Whether it is appropriate would depend on Carrie's situation and would thus not be at Anita's discretion. The discretionary quality of requests could not be traced back to the valuing-

\footnotetext{
9 „Anita has a reason to let Carrie into her house, if Carrie asks, and if Anita places sufficient discretionary value in Carrie"(Lewis 2018: 13).

${ }^{10}$ Lewis draws here from a longer discussion from Samuel Scheffler's "Equality and Tradition" (Scheffler 2010), see Lewis (2018: 6).
} 
attitudes the requestees have no reason to hold. If this was the case Lewis' model would not explain the discretionary quality of requests. ${ }^{11}$ Of course, Lewis's view of valuing might be correct. It is, however, not obvious that it is and thus not obvious that he is able to account for the discretionary quality of requests.

\section{Triggering Reasons}

Let us move on to the account of the reason giving force of requests that has been put forward by David Enoch (Enoch 2011). Enoch thinks that requests are reason-giving in a robust sense. They provide us with reasons in a robust sense by triggering already obtaining reasons of a particular kind (Enoch 2011: 9). Let me explain. The requester has the intention to give the requestee a reason to do as requested. By communicating her intention the requester gives the requestee a reason provided that there is a conditional reason which is triggered by the request. This is how this view is summarized by Enoch (Enoch 2011: 15):

(i) $\mathrm{A}$ intends to give $\mathrm{B}$ a reason to $\Phi$.

(ii) $\mathrm{A}$ intends $\mathrm{B}$ to recognize this intention;

(iii) A intends B's reason to $\Phi$ to depend in an appropriate way on B's recognition of A's communicated intention to give $\mathrm{B}$ a reason to $\Phi$

On this view the reason B has to $\Phi$ depends on his recognition of the communicated intention. Imagine that B recognizes A's intention to give him a reason to $\Phi$. B does so but he might have no reason to $\Phi$. The fact that B recognizes that A wants to give him a reason does not imply that $\mathrm{B}$ has a reason to $\Phi$. What does provide him a reason to $\Phi$ on this account? What is it that fills the gap between intention to give a reason and actually giving him a reason?

Enoch thinks that requests are triggering conditional reasons (Enoch 2011: 10). Yuma's asking John, for instance, triggers the reason "if-Yuma-asks-John-the-way-to-the-station-Johnhas-a- reason-to-tell-John-the-way-to-the-station". A conditional reason of the form "if-Yumaasks-John-the-way-to-the-station-John-has-a-reason-to-tell-Yuma-the-way-to-the-station" already obtained before Yuma asked John to tell him the way to the station. As the condition was satisfied the reason was triggered and John had a reason to tell Yuma the way to the station. The reason-giving force of requests depends on this view on a normative structure that is already in place. If there was no conditional reason the requests could have no reason-giving force.

Are requests triggering conditional reasons? I think that Enoch is right in thinking that a request gives us reasons against a background of a normative structure that is already in place. It is the value of the ability of giving others reasons by requesting that is required to give

\footnotetext{
${ }^{11}$ One could argue that Lewis might counter this objection by amending his account. On an amended account, two things are required for a request to be reason-giving: a) the requestee has to place value in the requester and b) doing so has to be appropriate. The problem is that this account does not fit with Lewis's view of the discretionary quality of requests. On his view, their reason-giving force is entirely up to the requestee. However, on the amended account, it would only be partly up to the requestee. That's because, while a) is up to the requestee, $b$ ) is not. So the reason-giving force of a request would only be up to the requestee if placing value in the requester was appropriate. Then the force of the request would be up to the requestee's valuing the requester. In all other cases, the reason-giving force of the request would not be up to the requestee. If the requestee places value in the requester but doing so is not appropriate, the request would not be reason-giving.
} 
requests its reason-giving force. It might be true that requests bring reasons into existence by triggering them. However, Enoch's proposal does not and arguably does not want to tell us anything about the background conditions the triggering of reasons by requests depends on. He tells us that this is what requests do. On his view there is a conditional reason of the sort "IfYuma-asks-John-to-tell-him-the-way-John-has-a-reason-to-do-so". But we do not know what is going on here. Enoch is suggesting that the normative change has to do with a communicated intention which is recognized by the requestee. The real question is, however, where those reasons are coming from and why we ought to believe that they obtain. Thus, we do not get an account of what is doing the normative work of creating reasons for the addressee.

My proposal provides us with an account for the reason-giving force of requests. We have the normative ability to create reasons by making requests. It is valuable for us to have this normative power ourselves and it is valuable for us that others have this normative power. That is to say, it is valuable for us that others have the power to create reasons by making requests that are respectful. The power others have is valuable for the requestees because it has the potential for creating valuable forms of interaction and relationships. Thus it is the tact of asking another person to do something that gives the addressee a reason to do as requested, provided that the request is respectful.

\section{Conclusion}

If Yuma asks John to tell him the way to the station John has a reason to do so. Yuma's request creates a request-dependent reason for John. Creating an additional reason is what making a request is all about. Requests are not mere communications of information. They are attempts to make a normative difference. It is valuable that we have the power to make this normative difference. It is valuable for us as requesters and it is valuable for us as requestees. The later holds because the normative power to create reasons by making requests that are respectful opens up a potential for valuable forms of interaction and relationships to which we would otherwise have no access.

Acknowledgements For helpful feedback and comments on earlier drafts of this paper I would like to thank Susanne Boshammer, David Enoch, Gerhard Ernst, Anna Goppel, Benjamin Kiesewetter, Felix Koch, Jens Kulenkampff, Erasmus Mayr, Andreas Müller, Stefan Riedener, Tobias Rosenfeldt, Nico Scarano, Thoms Schmidt, Jay Wallace and two anonymous referees for Ethical Theory and Moral Practice.

Funding Open Access funding provided by Universität Zürich.

Open Access This article is licensed under a Creative Commons Attribution 4.0 International License, which permits use, sharing, adaptation, distribution and reproduction in any medium or format, as long as you give appropriate credit to the original author(s) and the source, provide a link to the Creative Commons licence, and indicate if changes were made. The images or other third party material in this article are included in the article's Creative Commons licence, unless indicated otherwise in a credit line to the material. If material is not included in the article's Creative Commons licence and your intended use is not permitted by statutory regulation or exceeds the permitted use, you will need to obtain permission directly from the copyright holder. To view a copy of this licence, visit http://creativecommons.org/licenses/by/4.0/. 


\section{References}

Cupit G (1994) How requests (and promises) create obligations. In: The Philosophical Quarterly vol. 44, 177, 439-455

Enoch D (2009) Wouldn't it be Nice if p, therefore, p (for a moral p). In Utilitas, 21/2: 222-224

Enoch D (2011) Giving practical reasons. In: Philosophers' Imprint, 11/4: 1-22

Gläser M (2019) The normative structure of request. In: Timmons M (ed) Oxford studies in normative ethics, vol 9. Oxford University press, Oxford, pp 29-49

Lance M \& Kukla R (2013) Leave the gun: take the cannoli! The pragmatic topography of second-person calls. In: Ethics 123/3: 456-478

Lewis J H P (2018) The discretionary normativity of requests. In: Philosophers' Imprint 18/20: 1-16

Owens D (2012) Shaping the normative landscape. Oxford UP, Oxford

Raz J (1975) Practical reason and norms. Oxford UP, Oxford

Raz J (1986) The morality of freedom. Oxford UP, Oxford

Raz J (2009) The Authority of law. Essays on law and morality (2nd edition). Oxford UP, Oxford Scheffler S (2010) Equality and tradition. Questions in Moral and Political Philosophy, Oxford UP

Publisher's Note Springer Nature remains neutral with regard to jurisdictional claims in published maps and institutional affiliations. 